\title{
CARTOGRAFIAS GEOGRÁFICAS: O QUE PODE UM MAPA...
}

\author{
Djeovani Roos* \\ Universidade Federal da Grande Dourados \\ Cláudio Benito O. Ferraz ${ }^{* *}$ \\ Universidade Estadual Paulista
}

\begin{abstract}
Resumo: Pensar o mapa é pensá-lo como o agenciamento de forças, de linhas/corpos que se afetam e apontam para sentidos de localização e orientação espacial. Desdobra-se que os mapas não se restringem a representação plana da superfície terrestre, logo, há outras formas de se relacionar e vivenciar as representações que o processo de mapeamento promove. A espacialidade constitui-se na multiplicidade, e a relação da cartografia deve estar inclusa nessa maleabilidade espacial, sendo o mapa o próprio acontecer do mundo. 0 que faz de um ser um mapa é uma das prerrogativas eloquentes que recaem sobre o processo de mapeamento. Assim, intentamos que capturar e mostrar informação espacial são modos de apreensão de um possível do que faz uma imagem cartográfica ser um mapa. Realça-se que os sentidos deste trabalho situam-se no intuito de pensar sobre as possibilidades e potencialidades referentes aos processos cartográficos e à criação de mapas. Buscando deslocar o pensamento cartográfico, friccionando as suas dimensões comunicativa e informativa à qual ela se vincula atualmente. A potência que se instaura aqui é instigar o pensamento na relação dos mapas com a produção artística; enquanto obra de arte não se fixa representativamente, mas é um instigador de processos possíveis. O mural "Polimorfia Fronteiriça", exposto na FCH/UFGD, entra aqui como um possível na articulação com o pensamento geográfico e cartográfico, em que os mapas se vislumbram na contingencialidade criativa do pensar/viver o mundo enquanto lugar. Palavras-chave: Mapa. Cartografias geográficas. Multiplicidades. Pensamento geográfico.
\end{abstract}

GEOGRAPHICAL CARTOGRAPHY: WHAT CAN A MAP...

Abstract: Think the map is think of it as the freight forwarding, forces of lines/bodies affect and point to senses of place and spatial orientation. Unfolds that the maps are not restricted to flat representation of the Earth's surface, so there are other ways to relate and experience the representations that the mapping process promotes. The spatiality is constituted in the multiplicity and the relationship of cartography should be included in the suppleness and the spatial map of the world happen himself. What makes a map is one of the prerogatives eloquent that fall on the mapping process. Thus, we capture and show spatial information are modes of apprehension of a possible of what makes an image be a cartographic map. Emphasises that the directions of this work are in order to think about the possibilities and potentialities for the Cartographic processes and creating maps. Seeking to shift cartographic thought, rubbing their communicative and informational dimensions to which she links these days. The power which introduces here is instigating the thought in relationship of maps with artistic production; While artwork is not fixed but representatively is an instigator of possible processes. The mural "Polimorfia Fronteiriça", exposed on FCH/UFGD, comes here as a possible in conjunction with the geographic and cartographic thought, in which the maps are glimpsing at contingencialidade creative thinking/living the world while place.

Keywords: Map. Geographical Cartography. Multiplicities. Geographic Thought.

\section{CARTOGRAFÍA GEOGRÁFICA: QUÉ PUEDE UN MAPA...}

Resumen: Creo que el mapa es pensar como el manejo de fuerzas, de líneas y órganos afecta y sentidos de lugar y orientación espacial. Revela que los mapas no se limitan a la representación plana de la superficie terrestre, como hay otras formas de relacionar y las representaciones que promueve el proceso de asignación de experiencia. La espacialidad se constituye en la multiplicidad y la relación de la cartografía se debe incluir en este espacio flexible y el mapa del mundo se suceden. Lo que hace que un mapa es una de las prerrogativas elocuentes que caen en el proceso de asignación. Así, capturar y mostrar información espacial son modos de aprehensión de un posible de lo que hace que una imagen sea un mapa cartográfico. Hace hincapié en que las instrucciones de este trabajo son para pensar acerca de las posibilidades y potencial de los procesos cartográficos y crear mapas. Buscando cambiar el pensamiento cartográfico, frotando su dimensión comunicativa e informativa a la que se vincula. La energía que se presenta aquí es promover el pensamiento en la relación de los mapas con la producción artística; mientras que el arte no es fijo pero representativo es un instigador de procesos posibles. El mural "Polimorfia Fronteiriça", expuesto en FCH/UFGD, viene aquí como un posible junto con el pensamiento geográfico y cartográfico, en que el encuentro mapas contingencialidade creativo pensamiento estar del mundo mientras al lugar.

Palabras-clave: Mapa. Cartografía Geográfica. Multiplicidad. Pensamiento Geográfico.

\footnotetext{
”Mestre em Geografia, membro do Grupo de Pesquisa Linguagens Geográficas. Rodovia Dourados / Itahum, Km 12 - Unidade II Cep: 79.804-970. E-mail: djeovani_roos@ yahoo.com.br

${ }_{*}^{*}$ Doutor em Geografia, professor do Departamento de Educação da FCT/UNESP de Presidente Prudente. Rua Roberto Símonsen, 305 - Pres. Prudente - SP, $19060-900$ E-mail: cbenito2@yahoo.com.br
} 
Introdução: As legendas que não vemos...

O que faz de uma representação cartográfica ser mapa?' Esse questionamento deriva de algo que o precede, e com esse pensamento o atravessa, qual seja, a partir do escrito por Espinosa sobre o que pode um corpo, caminhamos com Gilles Deleuze para pensar o mapa como corpo em aberto, como linhas e forças que "dispõe o corpo de tal maneira que possa ser afetado pelo maior número de modos" (DELEUZE, 2002, p. 61), modos esses que se territorializam enquanto forma espacial dos fenômenos.

Nesse aspecto, o mapa é o agenciamento dessas forças, dessas linhas/corpos que se afetam e apontam para sentidos de localização e orientação espacial. Mapa, nesse contexto, é o que o corpo pode produzir de sentidos espaciais enquanto intensividade dos fenômenos e não apenas a representação da distribuição extensiva destes. Mapa assim não é só o que é representado de maneira fixa em uma dada escala, mas é também o que está de fora, que se coloca para além e aquém do significável pelas legendas.

Difícil pensarmos na questão das legendas que não vemos quando os mapas já chegam até nós imbuídos desses elementos definidores da forma "certa" de elaboração de uma representação cartográfica. Mas, e se os mapas não possuírem essas padronizações, essa uniformização de processos matemáticos precisos (proporcionalidade em relação ao mundo real, codificação das informações a serem ali localizadas com rigor e veracidade, eficiência e atendimento às normas técnicas, assim como meios tecnológicos infalíveis de reprodução de dados), um mapa que não atenda esses princípios representacionais pode ser considerado um mapa?

Mesmo que ele forneça as localizações e orientações necessárias para os deslocamentos humanos, sendo a sua premissa representacional e informativa? Ora, as legendas que não enxergamos, as que estão de fora do que é eleito e apresentado por representações cartográficas uniformizadoras e fixadoras da complexidade e da dinâmica espacial, como desenhos e imagens que fazem referência a algum lugar ou situação espacial, podem ser significadas enquanto mapas? Por estarem de fora dos padrões considerados corretos, será que essas legendas não podem apresentar outras formas de significação de sentidos espaciais?

Esses questionamentos nos instigam a pensar que tais legendas e imagens podem ser entendidas como mapas, mas que não se restringem aos parâmetros representacionais da ciência cartográfica maior, mas dessa concepção dominante derivam, permitindo

${ }^{1}$ Esse questionamento desdobrou-se das discussões ocorridas na disciplina "Tópicos Especiais I: Cartografia Geográfica e Pensamento Espacial", ministrada pela Profa ${ }^{D} r^{a}$ Gisele Girardi, no Programa de Pós-Graduação em Geografia da UFGD, juntamente com atividades no interior do Grupo de Pesquisa Linguagens Geográficas (GPLG). oferecer para o nosso entendimento outras perspectivas, leituras e pensamentos da dinâmica espacial do mundo, visões e expressões de um pensamento em devir menor (DELEUZE; GUATARRI, 2011; OLIVEIRA JR., 2009). Isto é, ao não se priorizar pelas uniformizações se adquirem os teores das vivências que entram em contato e se comunicam espacialmente. A cada passo na rua a cartografia está presente, os caminhos estão sendo mapeados pelo nosso deslocar, por nossos corpos, mesmo que isso ocorra despercebidamente. Talvez esses sejam os caminhos mapeáveis das cartografias geográficas em seu sentido mais subversivo, que rompe com os limites do considerado como único.

Podemos recorrer aos mapas, grosso modo, como representações espaciais que possibilitam os homens se localizarem e se orientarem espacialmente. Por esse modo que se destacam as suas significações estratégicas de uso e controle do território e se definem a uniformidade territorial passível de controle e o uso por ordem das forças e máquinas de Estado (DELEUZE; GUATTARI, 2011).

Destacamos aqui para as questões de que os mapas não necessariamente são as definições engendradas pelo Estado-Nação das composições territoriais, delimitadas pela necessidade de fixar os fenômenos a serem representados, portanto, tentando eliminar os processos que geram confusão e impedem a higienização de leituras e elaboração de modelos padronizadores de intervenção (WOOD, 2003; 2013).

Percebemos que o que fica de fora desse modelo representacional são forças que configuram toda uma dinamicidade espacial, com a diversidade de escalas dos múltiplos fenômenos que fazem a vida acontecer de maneira contingencial e em constante mobilidade. São referenciais de leitura espacial que permitem nos localizarmos na dinâmica espacial do mundo. Ou seja, os mapas não se resumem apenas a uma representação geométrica do espaço, de um espaço fixo, uma representação estática dos fenômenos espaciais, mas eles são compostos pela dinâmica espacial em que se encontram inseridos (DEL CASINO; HANNA, 2006; GIRARDI, 2009).

Usualmente, a palavra mapeamento pode ser designada para várias situações que não se fixam exatamente em representações cartográficas. Ela pode exercer diversas funcionalidades que se remetem a mapeamentos, logo, observa-se que os mapas não são estruturas cartográficas fixas, pois são engendrados pela dinâmica espacial do homem no mundo. As variáveis de mapeamento são múltiplas, concernentes com o caráter de possibilitar a localização dos fenômenos, permitindo ao pensamento estabelecer conexões nos deslocamentos manifestados na espacialidade. Como Doreen Massey (2009, p. 161) afirma: "Mapas, naturalmente, variam", isso visto nas categorizações políticas que vão decifran- 
do e orientando a dinâmica do mundo.

O que faz de um mapa ser um mapa é uma das prerrogativas eloquentes que recaem sobre o processo de mapeamento, rasurando o sentido tido como único das categorizações cartográficas que estruturam bases como sendo as "certas" para a constituição de mapas, descartando as possibilidades de se constituir mapas fora dessas bases uniformizadas (COSGROVE, 2008). Ou, ao se fazer isso, não são considerados enquanto mapas.

0 que estamos pontuando aqui é que os mapas podem ser constituídos para além das uniformizações e padronizações cartográficas, e que ao se fazer isso abre para uma gama maior de possibilidades da leitura e expressão da forma espacial dos fenômenos (SANTOS, 2007), e para um conjunto maior de informações que forneçam as localizações e orientações para se deslocar espacialmente na interação com os fenômenos. E que não necessariamente essas informações e expressões espaciais necessitam estar imbuídas em padrões fixadores de referenciais cartográficos para que seja possível ler e pensar o mundo enquanto dinâmica espacial (GIRARDI, 2009).

Vejamos então outras possibilidades de nos relacionarmos com os mapas.

\section{Representar, localizar, orientar...}

Entende-se que a função da representação é dar visibilidade às manifestações que se pronunciam espacialmente (CRAMPTON; KRYGIER, 2008). Assim, vislumbra-se que os mapas, ao representarem as manifestações espaciais, estão incutindo os processos de localização e orientação nessa espacialidade, possibilitando a movimentação do homem espacialmente. Todavia, as funcionalidades dos mapas podem ser muito diversas e cada qual vai trazer informações referentes ao que se está expressando, contextualizando as multiplicidades de suas formas e funções.

\footnotetext{
Mapas são criações humanas, narrativas, mensagens, ideologias, discursos e construções socioculturais. E seria lastimável se desperdiçássemos o seu potencial como forma de comunicação, expressão e meio para apreender a realidade [...]. O mapa, na verdade, não é um produto, mas um processo (mapeamento) que não se reduz a levantamentos topográficos e geodésicos, medidas de precisão e formas materiais, mas que pode ser igualmente espiritual, político ou moral e incluir o que é lembrado, imaginado e contemplado (SEEMANN, 2012, p. 13).
}

As palavras de Seemann apontam para a ideia de que mapas não se restringem ao sentido da representação plana da superfície terrestre, conforme o modo hegemônico do pensamento sobre os mapas nos impõe. Mas é romper com essa ideia no sentido de que há outras possibilidades de se vivenciar as representações que os mapeamentos promovem, que os mapas expõem em suas formalizações e não necessariamente se fixam na representação plana do espaço, enquanto um plano extensivo. $\mathrm{O}$ que intenta é que os mapas estão inseridos na dinâmica espacial do mundo e a partir disso gestam outras formas de comunicar, expressar e apreender a realidade. Isto é, a espacialidade constitui-se na multiplicidade, e para tanto a relação da cartografia deve estar inclusa nessa maleabilidade espacial.

Saber onde estamos é uma tarefa que nos dispomos cotidianamente, e, para tal, sempre estamos a nos localizar, mesmo que inconscientemente, todo e qualquer corpo sempre está a exercitar essa habilidade, pois, ao nos sentirmos localizados, territorializamos nossos referenciais e desejos e passamos assim a nos constituir, nos relacionar com os outros e nos orientarmos em relação ao mundo (SANTOS, 2007).

Nesse universo é que as funções dos mapas/mapeamentos são intensificadas em nossas lógicas de vivências, pois ninguém gosta de se sentir perdido, sem referenciais espaciais que the permitam sentir-se com segurança, sem risco de vida e sobrevivência. Logo, essas elucubrações do dia a dia intentam-nos a pensar cartograficamente, a pensar nas estratégias das quais nos debruçamos na espacialidade, categorização que desfaz a leitura hegemônica (maior) de se pensar a cartografia a título de meramente uniformizar informações em uma dada escala de representação.

Na visão do que faz uma imagem cartográfica ser um mapa apreende-se um possível: capturar e mostrar informação espacial. Assim, o mapa passa a ser o próprio mundo em movimento, é um elemento da prática espacial que se encontra dentro de um contexto de nossas ações mundanas (GIRARDI, 2009). Mesmo que isso acarrete em consequências vinculadas à sua maneira de trabalhar e pensar.

Isso desperta o pensamento para o fato de que o mapa não se trata apenas de uma representação do mundo, mas ele também produz o mundo. Logo, a trajetória no espaço - em sua multiplicidade - é o mapeamento e não o seu sentido fixo numa dada escala de representação de certos fenômenos concernentes com a escala adotada (MASSEY, 2009). A partir disso, pode-se entender os mapas enquanto criação do mundo, deixando os sentidos representacionais (enquanto reprodução exata da realidade em uma dada escala fixa) de lado, pois criar o mundo é diferente de representar o mundo em uma uniformidade cartográfica.

Kitchin, Perkins e Dodge (2009) apresentam dois principais campos de fundamentos ontológicos e epistemológicos da cartografia: o representacional (o mapa é uma tradução gráfica de um mundo existente) e o pós-representacional (o mapa cria mundos tanto quanto o mundo cria mapas). Isso implica noções 
distintas de espacialidade e de prática cartográfica (GIRARDI, 2013, p. 80)

Por tais questões é que se enfatiza a existência do espaço dentro da própria linguagem do mapa, ou seja, não existe o espaço antes do mapa - mapa das práticas espaciais - como algo inerente às relações conflitantes que se desenrolam na dinâmica do mundo. Os mapeamentos são criações tangenciadas exatamente pelas relações que se estabelecem entre o espaço e o mapa, resultando no mapeamento dos fenômenos, mas que não se cessam nessa elementaridade linear do processo, pois as conjunturas produzidas e articuladas nos mapas continuarão reverberando as suas tensões espacialmente, nos efeitos que se intensificam no processo de localização, orientação e representação da dinâmica espacial do mundo.
A intenção neste trabalho situa-se no intuito de pensar sobre as possibilidades e potencialidades referentes aos processos cartográficos e a criação de mapas. Para, dessa forma, constituir um deslocamento no pensamento cartográfico, friccionando as suas dimensões comunicativa e informativa à qual ela atualmente se vincula quase que exclusivamente (OLIVEIRA JR., 2012). É intentar para o fato de que há outros referenciais de leitura e de se ver o mundo; e essas dimensões estão inseridas no processo criativo da cartografia, no processo de criação de mapas. Para melhor expor e fundamentar essa ideia, vejamos a imagem a seguir.

\section{IMAGEM I - POLIMORFIA FRONTEIRIÇA}

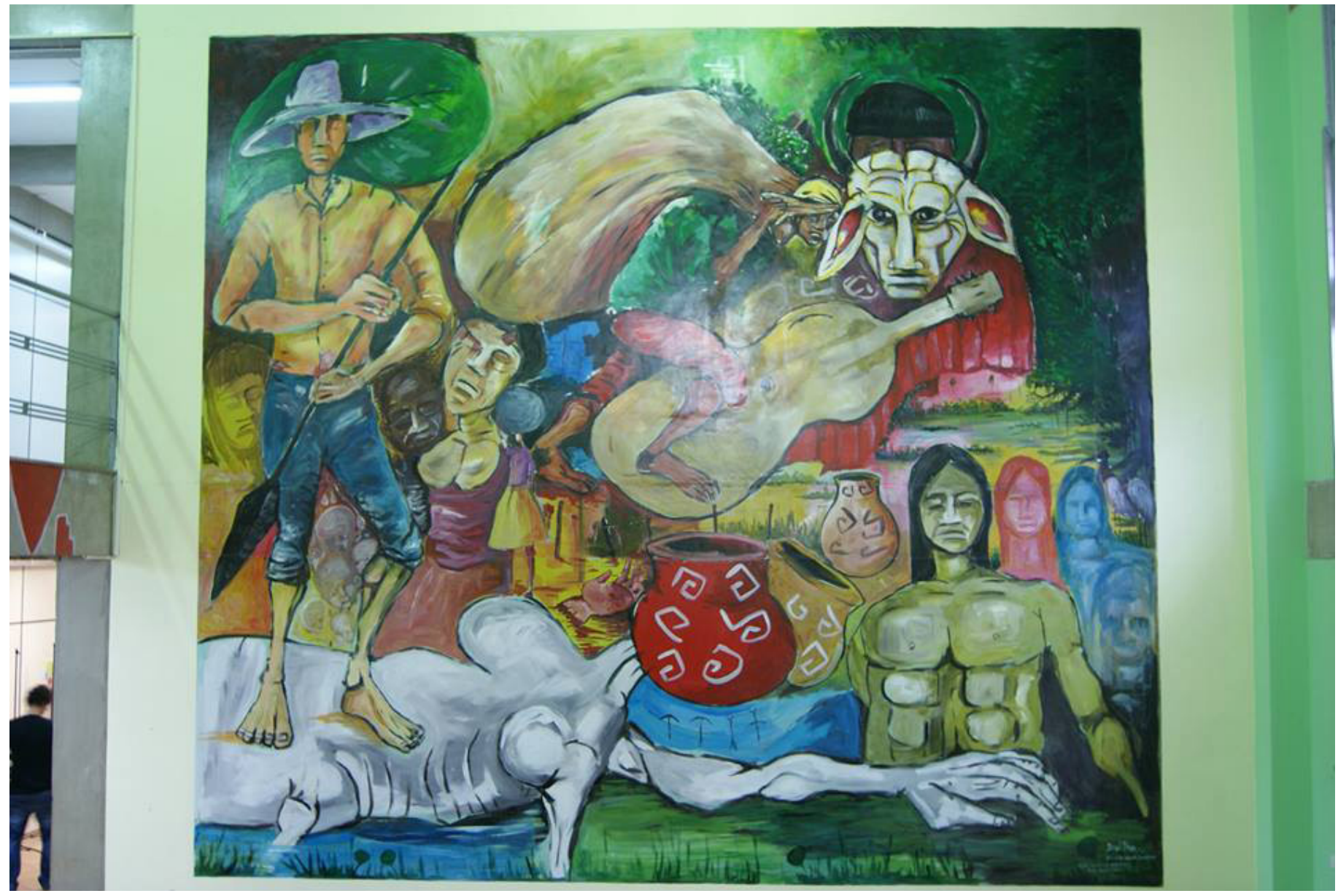

Fonte: Epaminondas Daltro Jr.: FCH/UFGD (Dourados/MS), 2013.

A imagem faz referência ao mural pintado por Epaminondas Daltro Jr., artista e pintor do Mato Grosso do Sul, e encontra-se exposta na parede do pátio central da Faculdade de Ciências Humanas $(\mathrm{FCH})$ da Universidade Federal da Grande Dourados (UFGD), localizada no município de Dourados/MS. Sabe-se, a título de informação, que essa obra foi elaborada com a intenção de expressar os diversos elementos presentes no contexto histórico e geográ- fico que perpassam pelas lógicas fronteiriças do Mato Grosso do Sul (Brasil).

Apesar desse adendo explicativo, de essa obra de arte abordar as contextualizações das fronteiras, para os parâmetros científicos maiores ela não se caracteriza como uma representação cartográfica da fronteira. Portanto, o que ela tem a ver com os mapas? Sua forma expressiva pode se deslocar para as bases cartográficas? Ela pode 
localizar e orientar espacialmente as manifestações humanas acontecidas em um território específico? Vamos ver até onde podemos chegar com tal experimentação interpretativa.

Observamos que a obra, ao expressar determinadas características espaciais articuladoras de um lugar, definindo uma região dita fronteiriça, está territorializando referenciais e fenômenos que possuem sua potência espacial, dando visibilidades às expressões territoriais, assim como expõe as fronteiras existentes nesses processos constitutivos do território.

Ao olharmos o mural, vamos identificando a representação de grupos de corpos e fenômenos constituidores dessa territorialidade. Percebemos uma figura que faz referência a uma cabeça de boi, e demarca assim o sentido da agropecuária como grande força econômica, mas é uma cabeça branca cujo contorno se confunde com um rosto humano - hibridações? Devir animal no homem? Não existe uma resposta precisa para tais dúvidas, mas podemos tentar um pouco de possível (DELEUZE; GUATTARI, 2011), ou seja, buscar criar sentidos possíveis, eis a potência em aberto por esta obra de arte, ou seja, um mapa não representacional, mas instigador de processos possíveis.

Mas, caminhemos com nossa experimentação, vemos outras figuras que remetem a formas dúbias, mas que nos afetam e que nos provocam a pensar, a projetar sentidos imagéticos sobre elas. Muito do que ali percebemos é territorializado enquanto sentido de um dado lugar a partir do que ali não está presente, estão de fora, virtualidades de uma realidade que nossa leitura atualiza.

Identificamos o artesanato e corpos indígenas como presença constante de uma história que muitos querem negar de injustiças e tragédias; o caboclo/pantaneiro como fruto de miscigenação e hibridação cultural; o pequeno produtor/violeiro como a população menos privilegiada, mas que constitui a força cultural enquanto lugar de vida e sobrevivência dos que se encontram no contexto da lógica de tensões e contatos fronteiriços; o ciclo da erva-mate presente no trabalhador carregando um saco com mate, demarcando um período fundamental na constituição das futuras cidades e de ocupação da região pelos não indígenas; a região pantaneira com suas águas e vegetação em meio a corpos deformados, como a dor e o drama das disputas por terras envolvendo fazendeiros e índios, pequenos proprietários e demais grupos humanos (migrantes e posseiros).

Interpretamos, por conseguinte, os indícios das formas de utilização do território que, ao serem transpostos para o mural, expressam os processos pelos quais esses vários fenômenos, em suas diferentes escalas de territorialização, se imbricaram, se tensionaram, se articularam para compor o imaginário hegemônico, apesar de fragmentado, com que muitos entendem ser a forma espacial desse lugar: o Mato Grosso do Sul fronteiriço.

Fazemos assim uma primeira aproximação com a potência cartográfica expressada por esse mural. Dessa forma o lemos como um mapa, um esboço imagético de diversas histórias que se desdobram no agora agenciador da multiplicidade espacial desse território.

Como dito, o mural "Polimorfia Fronteiriça" expressa detalhes da constituição temporal e espacial de um lugar, mas os detalhes artísticos são opções e seleções realizadas a partir dos elementos que afetaram o autor, mas que só se efetivam no encontro da obra com os que nela projetam sentidos, referenciais de localização e orientação de entendimento possível. A obra, dessa maneira, concentra um conjunto vasto de fenômenos por meio de um agenciamento de cores, linhas, traços e figuras, distribuídos ao longo de uma parede até então vazia de significantes pictóricos, mas que acabam por expressar referenciais espaciais quando do encontro com as imagens dos seus leitores; as pinceladas assim interpretadas rasuraram uma parede sem vida e apresentam retratos das peculiaridades da fronteira entre Brasil, Paraguai e Bolívia e dos polimorfismos que compreende o Estado do Mato Grosso do Sul.

E nesse próprio espaço, onde existia uma parede "vazia", neutra, é que se circunscreve a espacialidade, que se mapeia o espaço das fronteiras, pois a parede, que antes não apresentava rumo algum, agora se transformou, metamorfoseou-se, aderindo vários caminhos e sentidos com os traçados ali expostos. Não se trata de a parede ter tomado vida e consciência própria, mas sim dos elementos apresentados nos traços artísticos que referenciam as tensões dialógicas de um espaço em questão, trazendo sentidos outros, levando os indivíduos que ali entram em contato e se deparam com a expressividade da linguagem artística a pensar reflexivamente sobre o misto de componentes inseridos e representados por cores tracejadas e delineadas sobre uma parede antes "vazia". É nesse intuito espacial que as geograficidades se fazem presentes e que os mapas se vislumbram na contingencialidade criativa do pensar/viver o mundo enquanto lugar.

Por esses quesitos que a obra artística "Polimorfia Fronteiriça" é emblemática e fornece elementos para pensarmos essa obra enquanto mapa. Pois ela mapeia as contingências existentes no espaço e que se significam territorialmente, possibilitando uma leitura que perpassa pelo aspecto informativo e nos levam para as localidades em que esses conflitos se dão e estão expressos na linguagem artística. Ou seja, nos localizando e nos orientando na multiplicidade espacial, cartografias imagéticas que orientam o nosso pensamento no mapeamento dos elementos e fenômenos que compõem a territorialidade. 
As fronteiras estão expostas em linhas esboçadas, em que cada figura ali pintada está em conflito com as outras demais, num conjunto tenso de cores, luzes, sombras e formas não definidas em sua totalidade. Expressando nessa composição imagética os entre-lugares (FERRAZ, 2009), ou seja, os polimorfismos (as várias formas) da fronteira, não só a política administrativa, a que fixa e divide duas porções territoriais, mas a que coloca frente a frente os diversos: as fronteiras culturais internas a uma mesma extensão territorial de um Estado-Nação; as fronteiras entre os que usufruem das riquezas e dos que lutam para sobreviver; as fronteiras entre os que disputam as migalhas de uma vida dura e injusta, os que são marginalizados, negados e esquecidos; as fronteiras entre gêneros, como a quase ausência da figura feminina no mural tende a nos afetar etc.

Essa linguagem artística não é simplesmente uma representação do mundo enquanto reprodução exata de um dado lugar, ela transgride essa dimensão do pensamento e usurpa a lógica da formatação padronizada pela representação cartográfica. A sua composição não visa atender as normas da representação precisa do mundo como verdade definitiva. A grande força do sentido de mapa ali se coloca pelas potências do falso (DELEUZE, s/d), ou seja, não visa representar nem reproduzir a exatidão de um fenômeno, mas instigar sensações que provoquem o pensamento a pensar no que ali está de fora, naquilo que não está diretamente presente nas imagens e, contudo, com elas se relaciona por meio de toda a virtualidade do real que é ali atualizado por meio da trama de corpos e fenômenos figurada na obra (FERRAZ, 2009). $E$ é nesse sentido que sua expressividade enriquece a reflexão e a sua linguagem intensifica o pensamento. Seus traços são cartografias mapeando o espaço imageticamente.

Na pintura de Daltro Jr. não há uma tentativa de apresentar todos os fenômenos e elementos constituidores de região fronteiriça, não era esse o objetivo do artista, nem cabe a qualquer obra ter a pretensão de apresentar a totalidade do real, mas, ao focar alguns aspectos, os quais mais afetaram o imaginário do criador da obra, esses elementos ali figurados nos provocam, aos que entram em contato com essa obra, a agenciar sentidos que são atualizados do que ali se apresenta enquanto virtualidade, que está de fora mas intrinsecamente com aquelas imagens articuladas. Dessa maneira, agenciamos fenômenos que se encontram no contexto da história oficial constituidora daquela territorialidade, mas também daquilo que escapa dessa narrativa maior, dos aspectos marginais e que se tenta esquecer dessa narrativa de claro apelo ufanista e regionalista. Esses aspectos é que potencializam o sentido de mapa ali presentificado, pois não se restringe a querer representar o todo da realidade, mas instigar nossas sensações para o que falta, para o que não está dito ou pensado, para o fora.
O fora não é uma exterioridade material ou uma realidade conformada a uma verdade transcendente e idêntica a si mesma. Com o conceito de fora, Deleuze rejeita a questão metafísica da essência e sua necessidade puramente lógica, evita a crença num mundo verídico, o postulado de um pensamento naturalmente voltado para a verdade e o modelo da recognição. Esse conceito, por um lado, afirma a heterogeneidade e a diferença como elementos constituintes de um mundo imanente e, por outro, diz respeito a um devir do pensamento que se torna criativo ao afirmar o seu acaso, o seu devir e a sua multiplicidade (ABREU, 2007, p. 91-92).

Dessa forma, não vemos ali na pintura a imagem definida e nítida de índios sendo massacrados, nem a reprodução exata da luta de posseiros contra grandes latifundiários, nem a recognição precisa da derrubada de matas para plantio da erva-mate ou criação extensiva de gado etc., mas o conjunto e a distribuição das figuras, pela composição e tensão entre as cores, pelo jogo de luzes e sombras, assim como desfiguração e deformação dos corpos (o corpo branco de um boi esquartejado que se metamorfoseia em restos de corpos humanos, parte feminino, parte masculino; o esboço fantasmático de corpos indígenas e de negros que vão se esvaindo), mas também da sobreposição de corpos e imagens (o caboclo que se encontra sobre esse corpo branco e deformado está a empunhar uma lança indígena e, atrás dele, vemos um corpo parecido com algo feminino, mas de joelhos, sem face definida, em clara expressão de dor; a própria sobreposição de cores e tons, como o verde das matas se confundindo com o escuro das sombras etc. etc.).

Tudo isso aponta para uma sensação clara de tensões, conflitos, de mútuas incompreensões e injustiças a acontecerem como o trágico dessa territorialidade fronteiriça. Para tal, nosso pensamento, a partir de outras experiências espaciais, de leituras e estudos, é forçado a atualizar essa série de virtualidades, as quais não necessariamente representam e reproduzem fatos históricos específicos, mas reverberam as múltiplas estórias que acontecem até agora (MASSEY, 2009), são as potências do falso (DELEUZE, s/d) de fatos e fenômenos que não se restringem a verdades fixas, mas que acontecem como forças do "devir e a sua multiplicidade".

É nessas condições que essa composição artística se apresenta como sentido em aberto de mapa, não representa algo em si, mas nos instiga a perceber toda uma dinâmica constituidora dessa territorialidade com seus conflitos, tensões, belezas e tragédias. O mapa representacional de uma cartografia maior tenta informar tudo que se coloca como verdade, cabendo ao leitor apenas deduzir o sentido único de seus signos constituidores, daí sua legenda ser padronizada e impossibilitar outras interpretações. Tal mapa não força o pensamento a pensar, a criar outros sentidos, pois o mesmo já está de antemão definido. Já o mapa desdobrado da obra de 
Daltro Jr. só se realiza com nossa participação na criação de sentidos do que ali se apresenta, na interação entre o figurado em sua área pictórica com o que está fora desse limite. 0 mural acaba sendo um agenciador de corpos e enunciados, sendo um corpo de vetores de vários fenômenos em suas diferentes escalas de manifestação territorial e temporal (FERRAZ, 2009).

\section{Pensando sobre mapas, considerações...}

Dessa experimentação de leitura cartográfica a partir do mural "Polimorfia Fronteiriça", podemos caminhar numa direção de leitura que a referida obra traz para a desterritorialização de verdades fixadas como identidade de uma região fronteiriça, encenando as ambivalências dos conflitos que se expressam na dinâmica tensa e nômade do que se tenta delimitar como Mato Grosso do Sul. Como se pode observar na transfiguração do boi metamorfoseando-se em corpos humanos, essa imagem nos afetou e nos forçou a pensar nas disputas territoriais engendradas pela produção agropecuária na região, em que a exploração dessa produção ultrapassa os limites e significados humanos. Semelhante grau de violência se reverbera entre indígenas e representantes do agronegócio na disputa entre remarcação de terras e ampliação de área produtiva; o mesmo ocorre entre trabalhadores sem terras e grandes proprietários rurais.

Temos aí o repetir das injustiças sociais que ocorreram no processo de constituição desse lugar, mas que se repete sempre em sua diferença singular, uma temporalidade que se repete no espaço enquanto diferença; múltiplas dimensões espaciais que estão no jogo das forças políticas e das problemáticas que se inserem nessa espacialidade fronteiriça. Das diferentes culturas que se fazem presentes nesse espaço de relações diferenciadas que a fronteira se descreve e reinventa-se, designando os polimorfismos existentes na espacialidade.

Como não se pode deixar de notar, os mapas são estritamente políticos na composição de suas estratégias, por essa forma em que um dos seus elementos principais é possibilitar a localização dos fenômenos e a orientação espacial nas manifestações humanas (MOREIRA, 2012). E a obra "Polimorfia Fronteiriça" fornece elementos para a pensarmos como um mapeamento dos elementos territoriais manifestos em sua composição imagética. Isto é, um misto de expressividade que podemos pensar enquanto elementos cartografáveis da dinâmica da espacialidade, atravessados por outras intensidades que não se fixam numa forma padronizada da cartografia, das superfícies planas representadas. Fazendo uso de outros elementos que perpassam o mundo para mapear a dinâmica do mesmo.

Pelo simples fato de não se compor dentro das estruturações oficiais da linguagem científica maior, essa obra de arte, aqui ressignificada enquanto mapa, estabelece a possibilidade de derivas minoritárias na direção da constituição de uma linguagem menor da ciência geográfica, por meio de uma cartografia menor.

O conceito de maior em Deleuze e Guattari não tem o sentido de mais importante, numérica, ou, dimensionalmente, superior, mas sim, de estabilização, hegemonização, constância, metro padrão que serve para medir-se a si mesmo [...]. 0 menor é o que promove a variação e faz desestabilizar e expandir o maior e, assim, o devir é sempre a característica da minoridade. Cartografia menor é, então, esse movimento de crítica, da criação, da incorporação do maior para fazê-lo dizer outra coisa, de desestabilização do representacional (GIRARDI, 2013, p. 81).

Vemos assim que o sentido de menor não é substituir o da língua maior da ciência, num processo dialético de luta de contrários, mas de derivar desse maior outros sentidos minoritários esquecidos ou ignorados pelas forças e linhas maiores do pensamento científico. 0 menor, portanto, está na relação com o maior, deriva dele, mas, no sentido de rasurá-lo, o provoca em outros sentidos e direções. É nessa perspectiva de mapa em processo o que atualizamos da obra de Dalto Jr., é um mapa a apontar o movimento constante de fenômenos e corpos que a cartografia maior do Mato Grosso do Sul, que a geografia institucionalizada pelo Estado-Nação tendeu ou optou em não representar (LOIS, 2009).

Essa "opção" pode ser justificada pelo aspecto que a dinâmica espacial dos corpos não cabe num referencial que visa uniformizar informações e processos para assim fixá-los em uma dada escala matemática (MOREIRA, 2012), de maneira a torná-los passíveis de representação, daí o mundo sempre escapar, como linhas de fuga, por entre a vontade de representação verdadeira dos fatos almejada pelo discurso científico maior dessa cartografia. Eis a importância de se abrir para outros sentidos de mapas, capazes de apresentar a maior dinamicidade desses corpos e fenômenos constituidores da dinâmica espacial dos lugares (COSGROVE, 2008). Por isso a pertinência de a linguagem científica estabelecer intercessores com as linguagens artísticas, não para substituir o discurso de um pelo de outro, mas para ampliar as possibilidades de leitura espacial do mundo.

Mas, como já destacamos anteriormente, essa composição artística procede encontros entre a parede que a sustenta e os corpos que são afetados pelo que ali está imageado e, mesmo que de forma despercebida, tangencia formas de pensamento a partir desses encontros. Ao se valorizar a dimensão artística a partir do mapa, a possibilidade de se localizar e se orientar acontece no contexto e na dinâmica do próprio movimento da vida; o pensamento é forçado a pensar as camuflagens existentes nas entrelinhas dos referenciais que se pautam na representação de verdades fixas, que negam as rupturas, os vazios e a mobilidade dos corpos, as surpresas ine- 
rentes ao existir, as quais potencializam o sentido diferenciador da vida.

\begin{abstract}
Mas dentro do entendimento dominante de espaço do mapa "comum" no Ocidente, hoje, o pressuposto é, precisamente, de que não há espaço para surpresas. Exatamente como quando o espaço é compreendido como uma representação (fechada/estável) (a "espacialização" através da qual "surpresas são evitadas", De Certeau, 1984, p. 89); assim, nessa representação de espaço nunca perdemos o caminho, não somos, jamais, surpreendidos por um encontro com o inesperado, nunca enfrentamos o desconhecido [...]. Não percebemos as rupturas do espaço, o encontro com a diferença (MASSEY, 2009, p. 165).
\end{abstract}

O que Massey nos aponta é o processo restrito e centralizado que compõe os mapas atualmente, de um mundo já concebido, como se nele não houvesse mais transformações e que tudo já está delimitado, bastando-nos percorrer o mundo conhecido sem problema de surgir algo inédito, daí ela completar seu pensamento que no "mapa rodoviário não dirigimos fora dos limites do mundo conhecido. No espaço, como eu quero imaginá-lo, poderíamos" (MASSEY, 2009, p. 165). Não que devemos abandonar um mapa rodoviário, afınal ele é fundamental para nos orientarmos, contudo, ela está a apontar que o mundo vai muito além do que o Estado fixou como os caminhos que devemos percorrer (as estradas representadas no mapa rodoviário).

Se entendermos como mundo a só aquilo que se encontra representado num mapa, não conseguiremos nos orientar e nos localizar em relação a tudo que está de fora daquela representação, ou seja, de tudo que provoca surpresa, tanto de incômodo como de prazer. Aí que buscar o dinamismo diferenciador da vida ser necessário para nossa própria sobrevivência no mundo - temos que construir referenciais que nos possibilitem a locomoção para além do mundo conhecido.

São as possibilidades de instigar a pensar as potencialidades imaginativas do mundo pela linguagem cartográfica, nas composições de mapas diversos, em que esta não somente comunique, mas também expresse visões de mundo, configurações e imaginações espaciais (OLIVEIRA JR., 2012). Que, sobretudo, possibilite e permita os mapas serem rasurados para provocar outras localizações e orientações na espacialidade, intensificando a apreensão da dinâmica espacial do mundo. Foi nesse intuito que procuramos esboçar este ensaio reflexivo sobre os mapas e a linguagem cartográfica com a obra de arte "Polimorfia Fronteiriça", a qual é configurada por composições imagéticas, visualizando e destacando que essa obra pode ser potencialmente intensificada enquanto mapa pela sua constituição desestruturante que apresenta na composição de seus traços e tracejados artísticos.

"Fazer o mapa funcionar como outra coisa. E fazer outras coisas funcionarem como mapas" (OLIVEIRA JR.,
2012 , p. 40), esta seria uma perspectiva política para pensar os mapeamentos das polimorfias do mundo e o mundo enquanto mapa. Escapando das regras institucionalizadas ou descobrindo outras formas de se pensar, essa pode ser a polimorfia dos mapas e do ato de cartografar, grafando assim o espaço. 
ABREU, Ovídio. (2007) 0 fora e o signo. In: O que nos faz pensar, n. 22, p. 89-112, novembro. Disponível em: <http:// www.oquenosfazpensar.com/adm/uploads/artigo/o_fora_e_o_signo/22_O_fora_e_o_signo.pdf>. Acessado em: 22 nov. 2014.

COSGROVE, Denis. (2008) Cultural cartography: maps and mapping in cultural geography. Annales de géographie, v. 2, n. 660-661, p. 159-178. Disponível em: <http://www.cairn.info/revue-annales-de-geographie-2008-2-page-159. htm>. Acessado em: 20 out. 2014.

CRAMPTON, Jeremy. W.; KRYGIER, John. (2008) Uma introdução à Cartografia Crítica. In: ACSELRAD, Henri (org.). Cartografias sociais e território. Rio de Janeiro: IPPUR/UFRJ, p. 85-111. Disponível em: <www.ettern.ippur.ufrj.br/ publicacoes/58/cartografias-sociais-e-territorio>. Acessado em: 22 nov. 2014.

DELEUZE, Gilles. (s/d) Nietzsche e a filosofia. Lisboa: Rés Editora.

(2002) Espinosa: filosofia prática. São Paulo: Escuta.

DELEUZE, Gilles; GUATTARI, Félix. (2011) Mil platôs: capitalismos e esquizofrenia. Vol. 1. 2. ed. São Paulo: Editora 34.

DEL CASINO, Vincent J.; HANNA, Stephen P. (2006) Beyond the "binaries": A methodological intervention for interrogating maps as representational practices, ACME: An International. E-Journal for Critical Geographies, v. 4, n. 1, p. 34-56. Disponível em: <http://www.acme-journal.org/vol4/VDCSPH.pdf>. Acessado em: 12 nov. 2014.

FERRAZ, Cláudio Benito O. (2009) Geografia: o olhar e a imagem pictórica. Revista Pro-Posições, Campinas/SP, v. 20, n. 3 (60), p. 29-41.

FERREIRA, Álvaro Mendes. (2009) Abstração Espacial e a Cartografia da Idade Moderna. In: III Simpósio Luso-brasileiro de Cartografia Histórica, Ouro Preto. ANAIS III SLBCH, 2009. Disponível em <www.ufmg.br/rededemuseus/crch/ ferreira_abstracao-espacial-e-a-cartografia-da-idade-moderna.pdf>. Acessado em: 14 nov. 2014.

GIRARDI, Gisele. (2009) Mapas desejantes: uma agenda para a Cartografia Geográfica. Revista Pro-Posições, Campinas/SP, v. 20, n. 3 (60), p. 147-157.

(2013) Política e potência das imagens cartográficas na geografia. In: CAZETTA, Valéria; OLIVEIRA JR., Wenceslao M. (orgs.). Grafias do espaço - Imagens da educação geográfica contemporânea. Campinas (SP): Editora Alínea, p. 69-86.

HARVEY, David. (2012) O espaço como palavra-chave. Revista GEOgraphia, vol. 14, n. 28. Disponível em: <www.uff.br/ geographia/ojs/index.php/geographia/article/view/551/345>. Acessado em: 20 out. 2014.

KITCHIN, Rob; PERKINS, Chris; DODGE, Martin. (2009) Thinking about maps. In: (eds.) Rethinking Maps. Routledge. Disponível em: <http://personalpages.manchester.ac.uk/staff/m.dodge/Rethinking_Maps_Introduction.pdf>. Acessado em: 15 out. 2014.

LOIS, Carla. (2009) Imagen cartográfica e imaginarios geográficos. Los lugares y las formas de los mapas en nuestra cultura visual. Scripta Nova. Revista Electrónica de Geografía y Ciencias Sociales. Barcelona: Universidad de Barcelona, vol. XIII, n. 298. Disponível em: <http://www.ub.es/geocrit/sn/sn-298.htm>. Acessado em: 10 nov. 2014.

MASSEY, Doreen. (2009) Caindo nas armadilhas do mapa. In: MASSEY, Doreen. Pelo espaço: uma nova política da espacialidade. Rio de Janeiro: Bertrand Brasil, p. 159-165.

MOREIRA, Ruy. (2012) A representação e o olhar da geografia num contexto de espaço fluido. In: MOREIRA, Ruy. Geografia e práxis: a presença do espaço na teoria social crítica. São Paulo: Contexto, p. 179-186.

OLIVEIRA JR., Wenceslao Machado de. (2009) Grafar o espaço, educar os olhos. Rumo a geografias menores. Revista Pro-Posições, Campinas/SP, v. 20, n. 3 (60), p. 17-28.

(2012) Mapas em deriva: imaginação e cartografia escolar. Revista Geografares, Vitória/ES, n. 12, p. 1-49.

SANTOS, Douglas. (2007) O que é geografia? Texto inédito.

SEEMANN, Jörn. (2012) Carto-Crônicas: uma viagem pelo mundo da cartografia. Gurupi (CE): Editora Veloso.

WOOD, Denis. (2003) Cartography is dead (Thank god!). Cartographic Pespectives, NACIS, n. 45, p. 4-7.

(2013) Dogma visualizado: estado-nação, terra, rios. In: OLIVEIRA JR., Wenceslao Machado de; CAZETTA, Valéria. (orgs.). Grafias do espaço: imagens na educação geográfica contemporânea. 1. ed. Campinas: Alínea, v. 1, p. 23-51. 